\title{
ROTA DE PROCESSO PARA CONCENTRAÇÃO DE MINÉRIOS DE FERRO HIDRATADOS
}

G. C. LIPPER' e A. E. C. PERES ${ }^{1}$
'Departamento de Minas e Metalurgia - Universidade Federal de Minas Gerais
gunter_lipper@hotmail.com - aecperes@demet.ufmg.br
Artigo submetido em novembro/2013 e aceito em janeiro/2014
DOI: http://dx.doi.org/10.15628/holos.2014.1763

\section{RESUMO}

Este trabalho tem como objetivo desenvolver uma rota de processo para reduzir a influência negativa dos minérios hidratados, principalmente os goethíticos, na qualidade do concentrado de minério de ferro de alto teor. Foi comprovado que o circuito convencional de flotação deve ser dividido em grossos e finos, com esta divisão espera-se um ganho de $2 \%$ na recuperação mássica no concentrado final sem perda de qualidade. Além da amostra de concentrado da primeira etapa de obtenção de pellet feed, foram testadas outras amostras com níveis diferentes de hidratação em pH 7, utilizandose sulfato de sódio como ativador de superfície da hematita, aquecimento da polpa em 85으 para diminuir a tensão superficial e melhorar a estabilidade de bolhas e também foi testada a utilização de ultrassom para expulsão das partículas ultrafinas dos interstícios das partículas maiores e porosas. Foi então demonstrado que é possível flotar hematita e aumentar o teor de ferro no concentrado final em $0,5 \%$

PALAVRAS-CHAVE: minérios hidratados, goethita, flotação catiônica, sulfato de sódio, aquecimento da polpa, ultrassom.

\section{PROCESS ROUTE FOR THE CONCENTRATION OF HYDRATED IRON ORES}

\begin{abstract}
This study aims to develop a process route to reduce the negative influence of hydrated ores, mainly goethite bearing, in the quality of a high-grade iron ore concentrate. It was suggested that the conventional flotation should be divided in coarse and fine circuits; with this division one expects a gain of $2 \%$ in the mass recovery of the final concentrate without quality losses. Beyond the sample taken from the first pellet feed generation stage, experiments with other samples with
\end{abstract}

different levels of hydration were carried out using $\mathrm{pH} 7$, sodium sulfate as activator of the hematite surface, heating the slurry at $85 \circ \mathrm{C}$ to reduce the surface tension and improve the bubbles stability and ultrasound was also tested in order to expulse ultrafine particles from the interstices of larger and porous particles. So it was demonstrated that it is possible to float hematite and increase the Fe content in the final concentrate by $0.5 \%$.

KEYWORDS: hydrated minerals, goethite, cationic flotation, sodium sulfate, pulp heating, ultrasound 


\section{INTRODUÇÃO}

Algumas minas em fase de operação ou ainda em fase de estudos possuem litotipos com características peculiares as quais influenciam a qualidade do concentrado final de minério de ferro. Essas características, observadas principalmente nos minérios goethíticos, são alta porosidade (que pode em alguns casos ser correlacionada ao teor de PPC) e altos teores dos contaminantes como Al2O3, P, Mn, PPC etc.

Uma pequena revisão de técnicas de concentração ou de combinações de técnicas, pode ser útil para a compreensão e redefinição de rotas de processo nas instalações de beneficiamento existentes e em novas instalações. Porém, deve-se sempre ter em mente que um minério específico pode exigir modificações ou melhorias das técnicas atuais de concentração de tal maneira que não exista literatura sobre o assunto.

A compreensão do comportamento dos minerais em função das condições a que estão submetidos, em cada processo, deverá sempre ser objeto de pesquisas detalhadas para que as soluções de problemas de processo possam garantir da forma mais adequada todo o sucesso das operações de beneficiamento.

Este trabalho tem como objetivo desenvolver uma rota de processo para reduzir a influência negativa dos minérios hidratados, principalmente os goethíticos, na qualidade do concentrado de minério de ferro de alto teor utilizando de técnicas inovadoras na flotação as quais foram:

- Aumento da temperatura;

- Utilização de ultrassom;

- Flotação fracionada;

- Flotação direta aniônica.

Na flotação existe a possibilidade de transformação da superfície, ou seja, transformação de superfícies hidrofílicas em hidrofóbicas, através da adição criteriosa de determinados reagentes. A flotação deve ser necessariamente seletiva, sendo assim, a probabilidade de êxito do processo será tanto maior quanto mais distintas forem as superfícies das espécies a serem separadas.

A tensão interfacial mecanicamente é definida como o trabalho necessário para aumentar a área da superfície de uma unidade, num processo isotérmico e reversível. Quimicamente, temse que quanto maior a tensão superficial menor a disponibilidade da espécie para interagir com outras espécies. Sendo assim, a tensão superficial é a grandeza que permite a espumação na flotação, quanto menor a tensão superficial mais estáveis serão as bolhas.

A experiência mostra que a tensão superficial decresce com o aumento da temperatura. $\mathrm{Na}$ tabela 1 (RABOCKAI, 1979) é apresentada a tensão superficial da água em diversas temperaturas. 
Tabela 1 - Variação da tensão superficial da água com a temperatura, interface água-ar.

\begin{tabular}{c|c}
\hline $\mathrm{T}^{\circ} \mathrm{C}$ & $10^{3} \times \mathrm{\gamma}\left(\mathrm{N} \cdot \mathrm{m}^{-2}\right)$ \\
\hline 0 & 75,60 \\
\hline 20 & 72,75 \\
\hline 40 & 69,56 \\
\hline 60 & 66,18 \\
\hline 80 & 62,60 \\
\hline
\end{tabular}

Fonte - Rabockai, 1979.

A redução da tensão superficial com o aumento da temperatura é um fato previsível com base no princípio de Le Chatelier. Com o aumento da temperatura as espécies ficam mais disponíveis para interagir com o sistema e se concentrar na interface, logo a tensão superficial diminui.

Além da modificação da tensão superficial pelo aumento de temperatura outras técnicas foram investigadas como descrito por Iwasaki et al. (1960) que as características da flotação de goethita com reagentes aniônicos, entre os quais o dodecil sulfonato de sódio. Os autores realizaram testes de microflotação em tubo de Hallimond modificado e testes de flotação em bancada usando uma mistura artificial de quartzo e goethita. O ponto de carga zero da goethita foi determinado através de medidas de potencial de escoamento e o valor encontrado foi 6,7. $\mathrm{Na}$ Figura 1 é apresentada a recuperação de goethita em função do pH quando a dosagem de coletor (dodecil sulfato de sódio, dodecil sulfonato de sódio e cloreto de dodecilamônio) usada foi de 10 ${ }^{4} \mathrm{M}$.

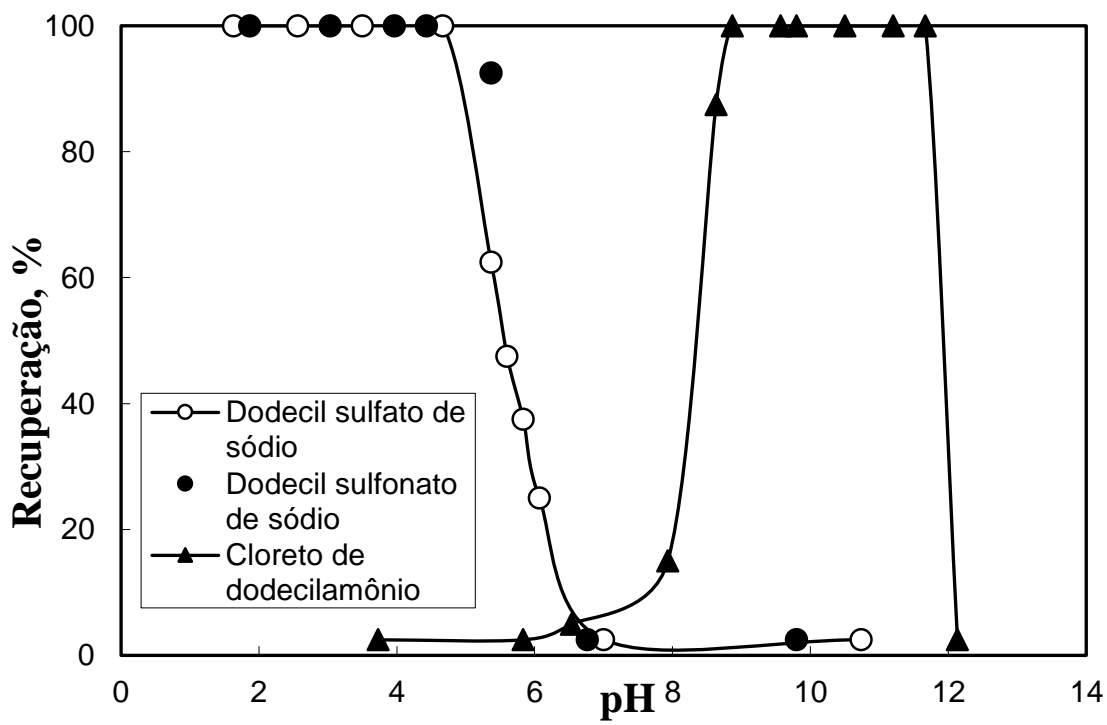

Figura 1: Recuperação de goethita em função do pH para diferentes coletores aniônicos e catiônico (IWASAKI, 1960)

Além disso, Lima (2010) concluiu que os atuais sistemas de flotação são alimentados por polpas contendo uma grande variedade de tamanhos de partículas minerais. Na flotação de óxidos e silicatos, a presença de partículas ultrafinas influencia negativamente o processo. Castro e Cruz (2003) comentaram que o tratamento separado de faixas de tamanho será necessário para minérios mais complexos ou mesmo para melhorar as recuperações e seletividade do processo. Frações de diferentes faixas de tamanho poderão ser condicionadas separadamente em meios 
mais adequados a elas. Tal procedimento tem mostrado várias vantagens, incluindo o aumento na taxa de flotação de grossos, o aumento na seletividade e redução do consumo de reagentes.

Outra técnica estudada por Cilek e Ozgen (2009) foi o uso do ultrassom na flotação e descreveram que ondas ultrassônicas podem ser usadas para melhorar a eficiência e/ou seletividade em processos de flotação. A maioria de seus estudos examinou o efeito do uso do ultrassom antes da flotação como, por exemplo, a remoção de camadas adsorvidas de reagentes em minerais e a emulsificação de reagentes de flotação.

Henriques (2012) sugeriu a partir dos resultados apresentados na tabela 2 que existe a possibilidade de separar a goethita de minerais hematíticos, efetuando-se a flotação da goethita em $\mathrm{pH}=7$, no qual a goethita apresenta o potencial zeta positivo (em torno de $10 \mathrm{mV}$ ) e as hematitas, com exceção da hematita mista Carajás, apresentam potencial zeta negativo (em torno de $-10 m V)$.

Tabela 2 - Resultados de PIE das hematitas da goethita e da magnetita, na presença de $\mathrm{KNO}_{3}$, por microeletroforese

\begin{tabular}{c|c}
\hline Amostra & pH PIE \\
\hline Hematita compacta & 6,2 \\
\hline Hematita especular & 5,3 \\
\hline Hematita martítica & 6,0 \\
\hline Hematita Carajás & 7,3 \\
\hline Goethita & 8,5 \\
\hline Magnetita & 2,9 \\
\hline
\end{tabular}

Fonte - Henriques, 2012.

\section{MATERIAIS E MÉTODOS}

As primeiras amostras testadas foram coletadas na região do nas Galerias de pesquisa geológica 8 e 9 na região de Apolo Norte. A Figura 2 apresenta uma fotografia da galeria 8.

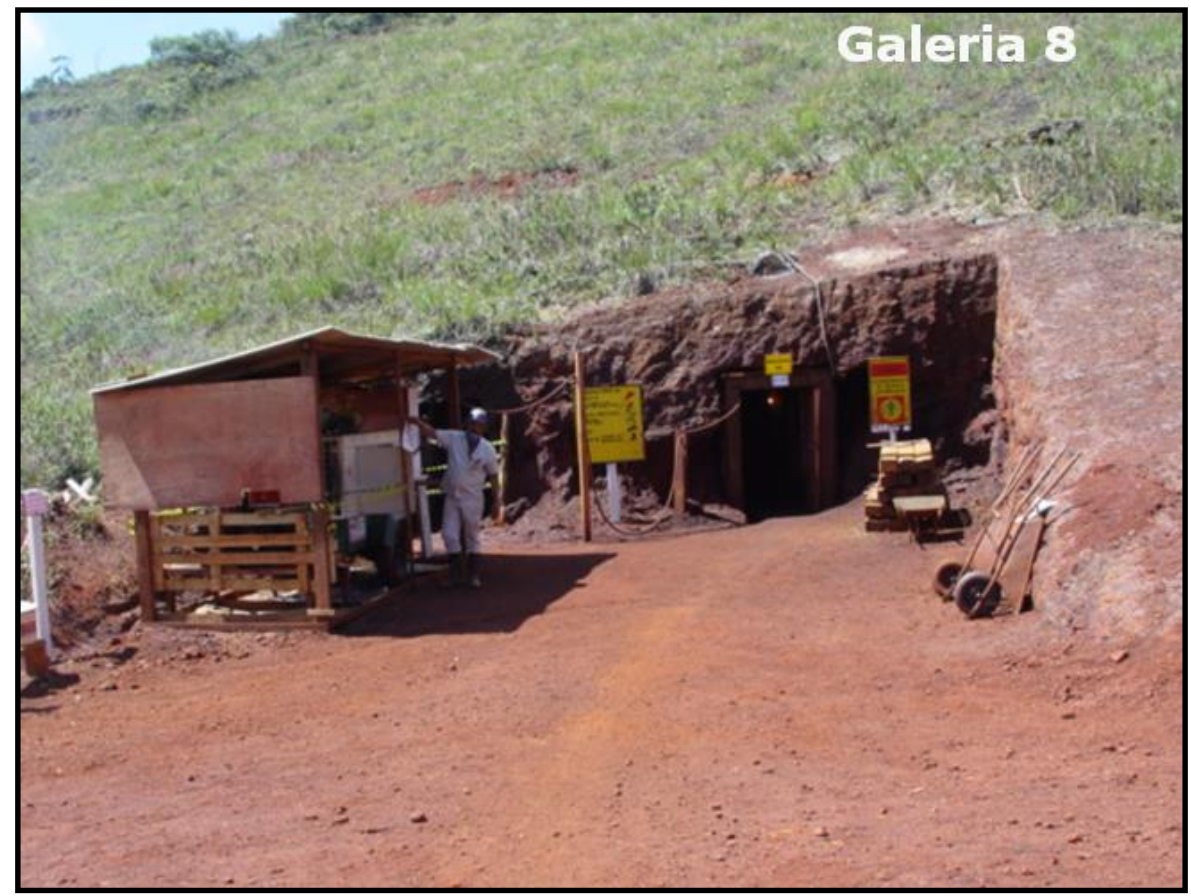

Figura 2: Foto de uma das galerias de pesquisa da região do Apolo (Santos, 2006). 
A massa retirada das galerias totalizou em torno de 150 toneladas de cada ROM. A Figura 3 apresenta as fotografias das pilhas dos dois tipos de minério extraídos.

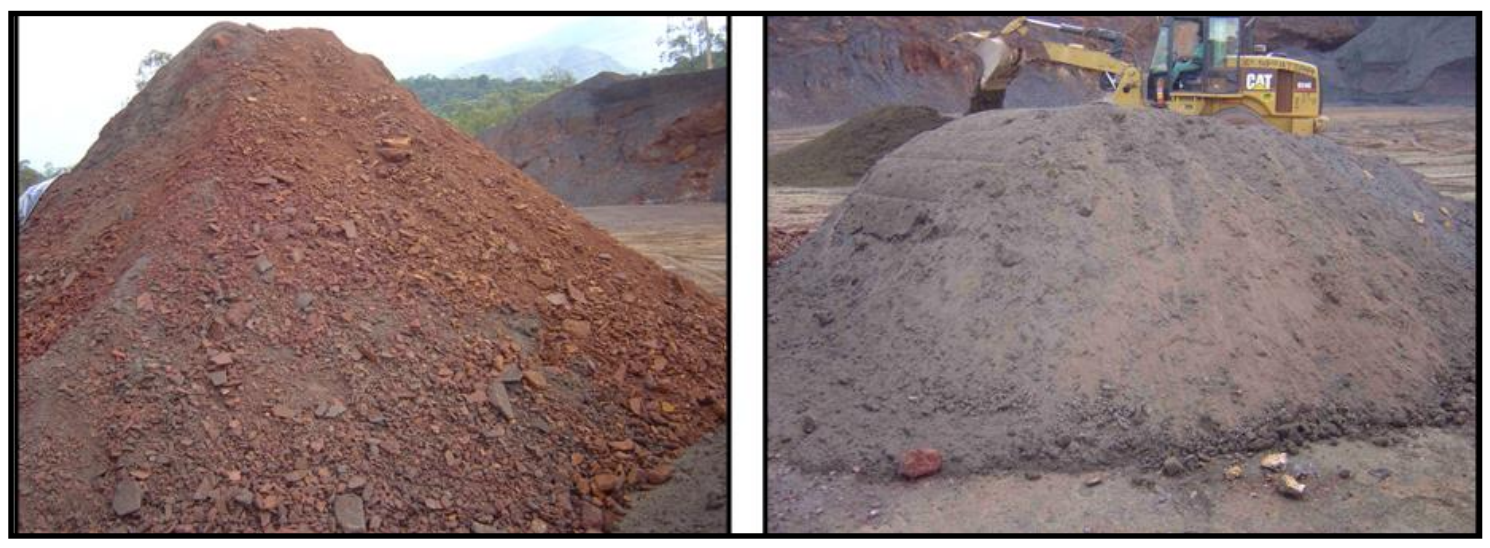

Figura 3: Foto das amostras de ROM goethítico e ROM itabirítico (denominado posteriormente como "rico") retiradas das galerias de pesquisa da região do Apolo (Santos, 2006).

Das amostras denominadas de ROM goethítico e ROM rico, surgiu uma nova amostra da qual foi a mistura de $50 \%$ de cada para compor o ROM blending, a qual também se insere no escopo deste trabalho.

Inicialmente foram enviados ao laboratório de processo $30 \mathrm{~kg}$ de cada amostra da alimentação de Apolo (run of mine $<8 \mathrm{~mm}$, ou seja, alimentação do Concentrador de Apolo) separados em dois pacotes de $15 \mathrm{~kg}$ cada de amostras, sendo estas:

- ROM rico

- ROM goethítico

- ROM blending (50\% rico e $50 \%$ goethítico)

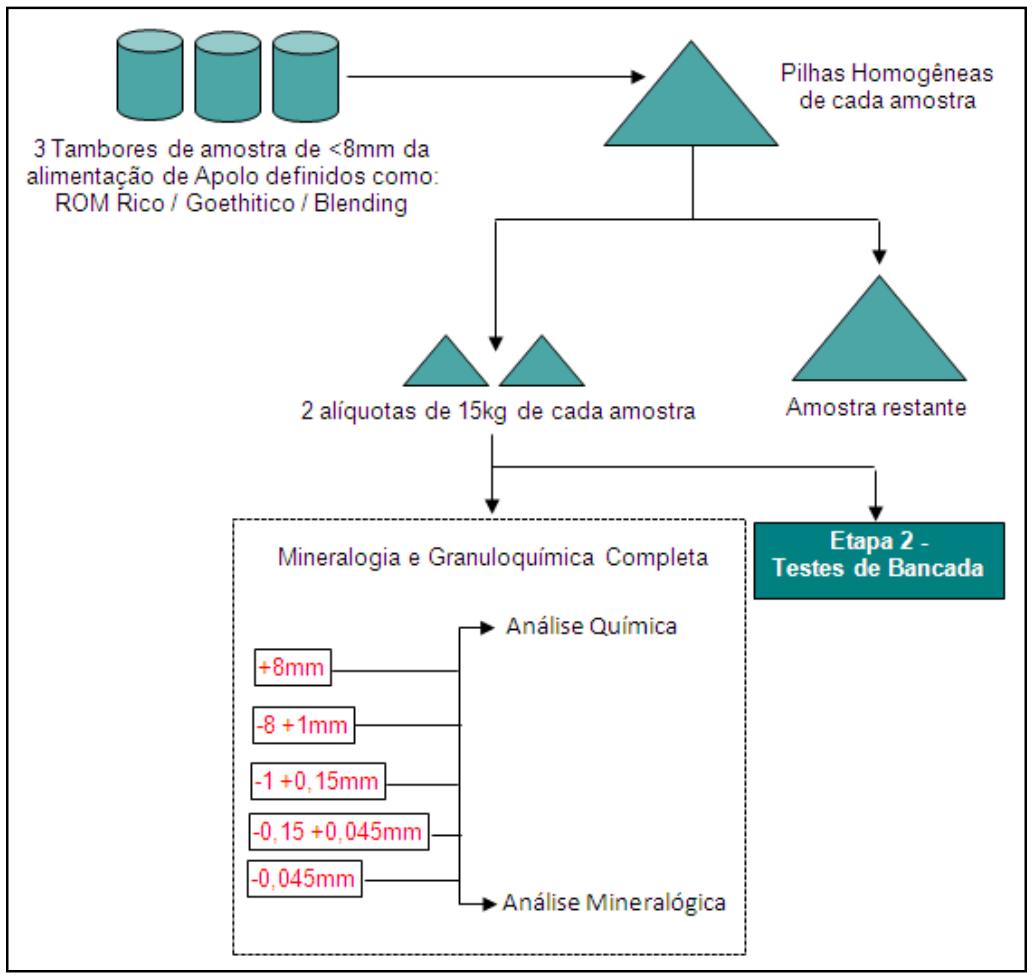

Figura 4: Programação das análises granuloquímica e mineralógica. (LIPPER 2012) 
Destas amostras, tomou-se inicialmente um pacote de $15 \mathrm{~kg}$ de cada um dos ROM's e efetuou-se um fracionamento em peneiras de laboratório nas seguintes malhas: $8 \mathrm{~mm} ; 1 \mathrm{~mm} ; 0,15$ $\mathrm{mm}$ e $0,045 \mathrm{~mm}$.

As alíquotas foram pesadas e quarteadas, sendo retiradas duas amostras de $100 \mathrm{~g}$ cada; uma das alíquotas foi enviada para análise mineralógica em microscópio óptico de luz refletida e transmitida com câmera Sony DXC-950 e placa Datatranslation 3154 acopladas para tomada de fotos. A outra alíquota foi enviada para o laboratório químico para análise química por fluorescência de raios-x em pastilha prensada. Além disso, foi disponibilizada a amostra integral do passante em 0,045 $\mathrm{mm}$ para determinação da quantidade de lamas (partículas $<10 \mu \mathrm{m}$ ) presentes no ROM em granulômetro a laser (marca Cilas). A Figura 4 esquematiza esta primeira etapa do estudo.

Em caráter complementar, foram efetuados mais dois testes denominados baterias 2 e 3 com duas amostras de pellet feed goethítico da Mina de Alegria com alto e médio níveis de hidratação denominadas amostra 4 e 2 respectivamente.

Os testes de flotação foram divididos em duas etapas:

- etapa A - flotação catiônica reversa de minério de ferro (separação de silicatos de minerais de ferro) com e sem separação no tamanho 0,045mm;

- etapa B - flotação aniônica direta de minério de ferro (separação de óxidos de ferro de hidróxidos de ferro).

Os testes de flotação catiônica reversa de minério de ferro, denominada etapa $A$, visaram a remoção de silicatos com a depressão de minério de ferro em $\mathrm{pH}=10,5$ como é feito atualmente na indústria. A tabela 3 apresenta a programação de testes desta etapa.

Tabela 3 - Programação da Etapa A de testes de flotação

\begin{tabular}{|c|c|c|c|c|c|}
\hline \multicolumn{6}{|c|}{ Testes de flotação fracionada } \\
\hline \multirow[b]{2}{*}{ Teste } & \multirow[b]{2}{*}{ Fração } & \multicolumn{4}{|c|}{ Reagentes } \\
\hline & & Amina $\left(g / t_{s i O 2}\right)$ & Amido (g/talim) & $\begin{array}{c}\text { Hexametafosfato } \\
\text { de } \mathrm{Na}\left(\mathrm{g} / \mathrm{t}_{\text {alim }}\right)\end{array}$ & $\mathrm{pH}$ \\
\hline 3 & \multirow{5}{*}{$\begin{array}{l}<0,15 \mathrm{~mm} \\
>0,45 \mathrm{~mm}\end{array}$} & 500 & 1000 & - & 10,5 \\
\hline 4 & & 500 & 1500 & - & 10,5 \\
\hline 5 & & 700 & 1000 & - & 10,5 \\
\hline 6 & & 700 & 1500 & - & 10,5 \\
\hline 7 & & 700 & 1000 & 60 & 10,5 \\
\hline 8 & \multirow{5}{*}{$<0,45 \mathrm{~mm}$} & 700 & 1000 & - & 10,5 \\
\hline 9 & & 700 & 1500 & - & 10,5 \\
\hline 10 & & 1200 & 1000 & - & 10,5 \\
\hline 11 & & 1200 & 1500 & - & 10,5 \\
\hline 12 & & 1200 & 1000 & 60 & 10,5 \\
\hline
\end{tabular}

Fonte - Lipper, 2012.

Após efetuar a primeira etapa de testes de flotação (etapa A), foram coletados os concentrados do melhor teste de grossos e finos e reunidos proporcionalmente para efetuar o teste de flotação aniônica direta de minério de ferro visando a separação de óxidos de ferro (hematita e magnetita) de hidróxidos de ferro (goethitas) com intuito de diminuir o teor de PPC e consequentemente aumentar o ponto metálico de Fe no concentrado final. Esta etapa 
denominada B foi acrescida de algumas variáveis as quais foram fundamentadas em alguns princípios conforme descrição a seguir:

- pH de flotação em 7: a partir de dados de Henriques (2012);

- aquecimento da polpa a temperatura de 85ㄷ: princípio de Le Chatelier (RABOCKAI, 1976);

- teste com ultrassom: teoria de Cilek e Ozgen (2009).

A tabela 4 apresenta a programação de testes.

Tabela 4 - Programação da Etapa B de testes de flotação, dosagem de amido $1000 \mathrm{~g} /$ talim, pH=7

\begin{tabular}{|c|c|c|c|c|c|c|}
\hline \multicolumn{7}{|c|}{ Etapa 2B flotação aniônica direta } \\
\hline \multirow{3}{*}{ Teste } & \multicolumn{6}{|c|}{ Condições } \\
\hline & \multirow{2}{*}{$\begin{array}{c}\text { Temperatura } \\
{ }^{\circ} \mathrm{C} \\
\end{array}$} & \multirow{2}{*}{$\begin{array}{c}\text { Uso } \\
\text { ultrassom }\end{array}$} & \multicolumn{2}{|l|}{ Coletor } & \multirow{2}{*}{$\begin{array}{l}\text { amina } \\
\mathrm{g} / \mathrm{t}_{\text {alim }}\end{array}$} & \multirow{2}{*}{$\begin{array}{l}\text { HMFNa } \\
\mathrm{g} / \mathrm{t}_{\text {alim }}\end{array}$} \\
\hline & & & tipo & $\mathrm{g} / \mathrm{t}_{\text {alim }}$ & & \\
\hline 1 & ambiente & - & sulfato de sódio & 50 & 50 & - \\
\hline 2 & ambiente & - & ácido oleico & 50 & - & - \\
\hline 3 & ambiente & - & sulfato de sódio & 50 & 50 & 60 \\
\hline 4 & ambiente & - & ácido oleico & 50 & - & 60 \\
\hline 5 & 85 & - & sulfato de sódio & 50 & - & - \\
\hline 6 & 85 & - & ácido oleico & 50 & - & - \\
\hline 7 & ambiente & $\operatorname{sim}$ & ácido oleico & 50 & - & - \\
\hline
\end{tabular}

Fonte - Lipper, 2012.

\section{RESULTADOS E DISCUSSÃO}

Efetuou-se a soma ponderada dos resultados nas frações acima e abaixo de 0,045 $\mathrm{mm}$ para então obter o resultado final para comparação com os testes de flotação sem separação. A tabela 5 apresenta a soma das referidas tabelas, bem como a qualidade prevista projetada pelo documento de processo do Projeto Apolo para comparação, denominada nas próximas tabelas apenas de "Projeto Apolo" (Fonte Vale, 2010).

Tabela 5 - Resultado da soma dos testes de flotação catiônica reversa de minério de ferro em $\langle 0,15 \mathrm{~mm}$ e $>$ $0,045 \mathrm{~mm}$ com $<0,045 \mathrm{~mm}$

\begin{tabular}{|c|c|c|c|c|c|c|c|c|}
\hline PF & \multicolumn{5}{|c|}{ Química global } & \multirow{2}{*}{$\begin{array}{c}\text { Rec. } \\
\text { Massa } \\
\%\end{array}$} & \multirow{2}{*}{$\begin{array}{c}\% \\
\text { ROM }\end{array}$} & \multirow{2}{*}{$\begin{array}{c}\text { Rec. } \\
\text { Met. } \\
\%\end{array}$} \\
\hline $\begin{array}{c}< \\
0,15 \mathrm{~mm}\end{array}$ & $\begin{array}{l}\mathrm{Fe} \\
\%\end{array}$ & $\begin{array}{c}\mathrm{SiO}_{2} \\
\%\end{array}$ & $\begin{array}{c}\mathrm{Al}_{2} \mathrm{O}_{3} \\
\%\end{array}$ & $\begin{array}{l}P \\
\%\end{array}$ & $\begin{array}{c}\text { PPC } \\
\%\end{array}$ & & & \\
\hline rico $(R)$ & 67,60 & 0,66 & 0,78 & 0,03 & 1,26 & 96,00 & 33,2 & 99,49 \\
\hline goethítico (G) & 66,61 & 0,73 & 1,27 & 0,04 & 2,21 & 94,33 & 22,1 & 98,48 \\
\hline$R+G$ & 67,10 & 0,69 & 1,02 & 0,03 & 1,74 & 95,17 & 27,6 & 99,24 \\
\hline Projeto Apolo & 65,55 & 1,08 & 1,81 & 0,17 & 2,57 & 87,91 & 25,5 & 96,22 \\
\hline
\end{tabular}

Fonte - Lipper, 2012.

A tabela 6 apresenta os resultados dos testes de flotação sem separação em 0,045mm para comparação dos resultados. 
Tabela 6 - Resultado dos testes de flotação catiônica reversa de minério de ferro sem separação em 0,045mm

\begin{tabular}{|c|c|c|c|c|c|c|c|c|}
\hline $\mathrm{PF}$ & \multicolumn{5}{|c|}{ Química global } & \multirow{2}{*}{$\begin{array}{c}\text { Rec. } \\
\text { Massa } \\
\%\end{array}$} & \multirow{2}{*}{$\begin{array}{c}\% \\
\text { ROM }\end{array}$} & \multirow{2}{*}{$\begin{array}{c}\text { Rec. } \\
\text { Met. } \\
\%\end{array}$} \\
\hline $\begin{array}{c}< \\
0,15 \mathrm{~mm}\end{array}$ & $\begin{array}{l}\mathrm{Fe} \\
\%\end{array}$ & $\begin{array}{c}\mathrm{SiO}_{2} \\
\%\end{array}$ & $\begin{array}{c}\mathrm{Al}_{2} \mathrm{O}_{3} \\
\%\end{array}$ & $\begin{array}{l}\mathrm{P} \\
\%\end{array}$ & $\begin{array}{c}\text { PPC } \\
\%\end{array}$ & & & \\
\hline rico $(R)$ & 67,74 & 0,48 & 0,77 & 0,03 & 1,39 & 94,06 & 32,6 & 97,71 \\
\hline goethítico (G) & 66,90 & 0,34 & 1,06 & 0,04 & 2,06 & 82,59 & 19,3 & 88,29 \\
\hline$R+G$ & 67,32 & 0,41 & 0,91 & 0,03 & 1,72 & 88,33 & 25,6 & 93,00 \\
\hline Projeto Apolo & 65,55 & 1,08 & 1,81 & 0,17 & 2,57 & 87,91 & 25,5 & 96,22 \\
\hline
\end{tabular}

Fonte - Lipper, 2012.

Comparando-se as duas tabelas, pode ser afirmado que:

- Não há comprometimento da qualidade com a separação em 0,045mm;

- A separação em $0,045 \mathrm{~mm}$ promoveu um aumento de $2 \%$ na recuperação mássica da flotação, que correspondeu a 6\% de aumento em recuperação metalúrgica.

A separação da flotação em $0,045 \mathrm{~mm}$ traz benefício para a flotação catiônica reversa de minério de ferro. Os testes da etapa $B$ foram realizados primeiramente com as amostras de concentrado da etapa A - bateria 1. Os resultados são apresentados na tabela 7.

Tabela 7 - Resultado da etapa B - bateria 1

\begin{tabular}{c|c|c|c|c|c|c|c|c|c}
\hline $\begin{array}{c}\text { Conc. Teste 5 } \\
\text { Etapa 2B } \\
\text { Bateria 1 }\end{array}$ & $\begin{array}{c}\mathrm{Fe} \\
\%\end{array}$ & $\begin{array}{c}\mathrm{SiO}_{2} \\
\%\end{array}$ & $\begin{array}{c}\mathrm{Al}_{2} \mathrm{O}_{3} \\
\%\end{array}$ & $\begin{array}{c}\mathrm{P} \\
\%\end{array}$ & $\begin{array}{c}\mathrm{PPC} \\
\%\end{array}$ & $\begin{array}{c}\text { Rec. } \\
\text { Massa } \\
\%\end{array}$ & $\begin{array}{c}\text { Rec. } \\
\text { Met. } \\
\%\end{array}$ & $\begin{array}{c}\text { Grau } \\
\begin{array}{c}\text { Enri- } \\
\text { quec. }\end{array}\end{array}$ & $\begin{array}{c}\text { Índice } \\
\text { seleti- } \\
\text { vidade }\end{array}$ \\
\hline rico (R) & 68,39 & 0,53 & 0,74 & 0,03 & 1,00 & 96,50 & 96,69 & 1,00 & 2,23 \\
\hline goethítico (G) & 67,60 & 0,51 & 0,53 & 0,04 & 1,51 & 85,45 & 86,29 & 1,01 & 3,06 \\
\hline $\mathrm{R}+\mathrm{G}$ & 67,57 & 1,27 & 0,65 & 0,04 & 1,22 & 72,19 & 72,66 & 1,01 & 1,84 \\
\hline
\end{tabular}

Fonte - Lipper, 2012.

Dos resultados obtidos, pode ser afirmado que:

- A utilização de ácido oleico não apresentou qualquer benefício à flotação;

- Das amostras de ROM rico e ROM blending não foi possível enxergar ganhos como previsto pela análise da alimentação, contudo pelos resultados da amostra de ROM goethítico pode-se concluir que quanto maior o nível de hidratação da amostra, maior é o efeito do sulfato de sódio associado ao aumento de temperatura.

Dando prosseguimento aos testes da etapa B, decidiu-se por efetuar testes complementares com uma amostra do pellet feed goethítico da Mina de Alegria da Vale com alto nível de hidratação denominada amostra 4. Esta etapa foi então denominada etapa B - bateria 2.

A qualidade química da amostra 04 de pellet feed goethítico da Mina de Alegria da Etapa 2B - Bateria 2 é apresentada na tabela 8. 
Tabela 8 - Qualidade química da alimentação dos testes da Etapa 2B - Bateria 2

\begin{tabular}{c|c|c|c|c}
\hline \multicolumn{5}{|c}{ Química global } \\
\hline $\begin{array}{c}\mathrm{Fe} \\
\%\end{array}$ & $\begin{array}{c}\mathrm{SiO}_{2} \\
\%\end{array}$ & $\begin{array}{c}\mathrm{Al}_{2} \mathrm{O}_{3} \\
\%\end{array}$ & $\begin{array}{c}\mathrm{P} \\
\%\end{array}$ & $\begin{array}{c}\mathrm{PPC} \\
\%\end{array}$ \\
\hline 58,01 & 3,02 & 1,55 & 0,083 & 11,06 \\
\hline
\end{tabular}

Fonte - Lipper, 2012.

É evidente que esta amostra é puramente goethítica, além disso esta amostra não se assemelha ao pellet feed previsto para o Projeto Apolo de 65\% de Fe. Logo, os testes da Etapa 2B - Bateria 2 foram estruturados da seguinte forma:

- Verificação do efeito do sulfato de sódio com e sem amina à temperatura ambiente;

- Verificação do efeito da temperatura da polpa à $85^{\circ} \mathrm{C}$ utilizando o sulfato de sódio com e sem amina.

Os resultados dos testes são apresentados na tabela 9.

Tabela 9 - Resultado dos testes da Etapa 2B - Bateria 2 com a amostra 04 de pellet feed goethítico da Mina de Alegria da Vale

\begin{tabular}{|c|c|c|c|c|c|c|c|c|c|c|c|c|c|c|c|c|c|c|c|}
\hline \multirow[b]{2}{*}{ Amostra } & \multirow[b]{2}{*}{ Teste } & \multicolumn{6}{|c|}{ Condições } & \multirow[b]{2}{*}{ Fluxo } & \multirow{2}{*}{$\begin{array}{c}\mathbf{R} \\
\text { Mássica } \\
(\%) \\
\end{array}$} & \multicolumn{9}{|c|}{ Química Global (\%) } & \multirow{2}{*}{$\begin{array}{c}\text { Rec. } \\
\text { Metálic } \\
\text { a (\%) }\end{array}$} \\
\hline & & $\begin{array}{l}\text { Temp. } \\
\text { oC }\end{array}$ & $\begin{array}{l}\text { Cole } \\
\text { Tipo } \\
\end{array}$ & $\begin{array}{l}\text { tor } \\
\text { (g/t Alim) }\end{array}$ & \begin{tabular}{|c|} 
Amina \\
(g/t Alim) \\
\end{tabular} & \begin{tabular}{|c|} 
Amido \\
(g/t Alim) \\
\end{tabular} & pH & & & $\mathrm{Fe}$ & $\mathrm{SiO}_{2}$ & $\mathbf{P}$ & $\mathrm{Al}_{2} \mathrm{O}_{3}$ & $\mathbf{M n}$ & $\mathrm{TiO}_{2}$ & $\mathrm{CaO}$ & MgO & PPC & \\
\hline \multirow{16}{*}{ 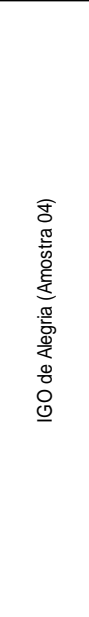 } & \multirow{4}{*}{1} & \multirow{4}{*}{ Ambiente } & \multirow{4}{*}{$\begin{array}{c}\text { Sulf ato de } \\
\text { Sódio }\end{array}$} & \multirow{4}{*}{50} & \multirow{4}{*}{ - } & \multirow{4}{*}{1000} & \multirow{4}{*}{7} & $\mathrm{AL}$ & 100,00 & 58,01 & 3,02 & 0,083 & 1,55 & 0,355 & 0,032 & 0,040 & 0,052 & 11,06 & \multirow{4}{*}{100,00} \\
\hline & & & & & & & & AL. Calc. & 100,00 & 58,02 & 2,89 & 0,083 & 1,48 & 0,354 & 0,032 & 0,040 & 0,030 & 11,13 & \\
\hline & & & & & & & & $\mathrm{CO}$ & 100,00 & 58,02 & 2,89 & 0,083 & 1,48 & 0,354 & 0,032 & 0,040 & 0,030 & 11,13 & \\
\hline & & & & & & & & $\mathrm{RJ}$ & 0,00 & & & & & & & & & & \\
\hline & \multirow{4}{*}{2} & \multirow{4}{*}{ Ambiente } & \multirow{4}{*}{$\begin{array}{l}\text { Sulf ato de } \\
\text { Sódio }\end{array}$} & \multirow{4}{*}{50} & \multirow{4}{*}{50} & \multirow{4}{*}{1000} & \multirow{4}{*}{7} & AL & 100,00 & 58,01 & 3,02 & 0,08 & 1,55 & 0,35 & 0,03 & 0,04 & 0,05 & 11,06 & \multirow{4}{*}{95,74} \\
\hline & & & & & & & & AL. Calc. & 100,00 & 57,98 & 2,91 & 0,081 & 1,50 & 0,346 & 0,032 & 0,037 & 0,048 & 11,11 & \\
\hline & & & & & & & & $\mathrm{CO}$ & 95,51 & 58,12 & 2,75 & 0,081 & 1,45 & 0,352 & 0,028 & 0,036 & 0,044 & 11,10 & \\
\hline & & & & & & & & $\mathrm{RJ}$ & 4,49 & 54,95 & 6,33 & 0,073 & 2,61 & 0,219 & 0,111 & 0,063 & 0,143 & 11,43 & \\
\hline & \multirow{4}{*}{3} & \multirow{4}{*}{85} & \multirow{4}{*}{$\begin{array}{c}\text { Sulf ato de } \\
\text { Sódio }\end{array}$} & \multirow{4}{*}{50} & \multirow{4}{*}{ - } & \multirow{4}{*}{1000} & & $\mathrm{AL}$ & 100,00 & 58,01 & 3,02 & 0,08 & 1,55 & 0,35 & 0,03 & 0,04 & 0,05 & 11,06 & \\
\hline & & & & & & & 7 & AL. Calc. & 100,00 & 58,13 & 2,89 & 0,081 & 1,50 & 0,355 & 0,032 & 0,038 & 0,028 & 11,13 & 989 \\
\hline & & & & & & & & $\mathrm{CO}$ & 98,85 & 58,16 & 2,89 & 0,081 & 1,48 & 0,356 & 0,031 & 0,037 & 0,026 & 11,11 & \\
\hline & & & & & & & & $\mathrm{RJ}$ & 1,15 & 55,94 & 2,76 & 0,080 & 2,93 & 0,235 & 0,110 & 0,088 & 0,222 & 12,52 & \\
\hline & & & & & & & & $\mathrm{AL}$ & 100,00 & 58,01 & 3,02 & 0,08 & 1,55 & 0,35 & 0,03 & 0,04 & 0,05 & 11,06 & \\
\hline & 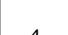 & 85 & Sulf ato de & 50 & 50 & 1000 & 7 & AL. Calc. & 100,00 & 58,14 & 2,90 & 0,082 & 1,52 & 0,340 & 0,031 & 0,038 & 0,023 & 11,12 & ๑० २० \\
\hline & 4 & 80 & Sódio & 50 & 30 & 1000 & 7 & $\mathrm{CO}$ & 99,22 & 58,17 & 2,87 & 0,082 & 1,51 & 0,341 & 0,030 & 0,038 & 0,021 & 11,12 & $\begin{array}{l}9,20 \\
\end{array}$ \\
\hline & & & & & & & & $\mathrm{RJ}$ & 0,78 & 53,96 & 7,12 & 0,074 & 2,81 & 0,234 & 0,103 & 0,070 & 0,275 & 11,72 & \\
\hline
\end{tabular}

Fonte - Lipper, 2012.

Da tabela 9 podem se extrair as seguintes conclusões:

- Os testes realizados com a amostra 04 não se apresentaram promissores devido ao fato que mais de $70 \%$ dos minerais de Fe presentes nessa amostra são goethitas, portanto para amostras com níveis extremos de hidratação, a flotação aniônica direta não funciona devendo ser adotada estratégia diferente de concentração, ou seja tratamento térmico;

- O sulfato de sódio em $\mathrm{pH}=7$ se comporta como ativador de superfície para separar partículas de goethitas das hematitas, pois ele individualmente no sistema não atua como coletor; portanto a utilização de amina é necessária como agente coletor;

- O aumento da temperatura melhora a ação do sulfato de sódio. 
Para diminuir as dúvidas finais desta Etapa 2B de testes causados pelo alto grau de hidratação da amostra 04 do pellet feed da Mina de Alegria, foi então escolhida a amostra 02 do pellet feed também da Mina de Alegria com um menor nível de hidratação para os testes da Etapa 2B - Bateria 3.

A qualidade química da amostra 02 de pellet feed goethítico da Mina de Alegria da Etapa 2B - Bateria 3 é apresentada na tabela 10.

Tabela 10 - Qualidade química da alimentação dos testes da Etapa 2B - Bateria 2

\begin{tabular}{c|c|c|c|c}
\hline \multicolumn{5}{|c}{ Química global } \\
\hline $\begin{array}{c}\mathrm{Fe} \\
\%\end{array}$ & $\begin{array}{c}\mathrm{SiO}_{2} \\
\%\end{array}$ & $\begin{array}{c}\mathrm{Al}_{2} \mathrm{O}_{3} \\
\%\end{array}$ & $\begin{array}{c}\mathrm{P} \\
\%\end{array}$ & $\begin{array}{c}\mathrm{PPC} \\
\%\end{array}$ \\
\hline 64,13 & 1,24 & 0,41 & 0,040 & 6,26 \\
\hline
\end{tabular}

Fonte - Lipper, 2012.

Esta amostra apresenta-se mais semelhante ao pellet feed previsto no Projeto Apolo contendo menor nível de hidratação que a amostra 04 da Bateria de testes anterior. Também se pode afirmar neste momento que pela correlação das análises mineralógica e química, o mineral que governa o teor de PPC é a goethita compacta.

Com base nas conclusões dos testes da Bateria 2, os testes da Bateria 3 foram estruturados da seguinte forma:

- Testes somente com alta temperatura para aumentar o efeito do sulfato de sódio, o qual foi definido nesta dissertação de ativador de superfície;

- Variação das dosagens de sulfato de sódio e amina.

Os resultados dos testes são apresentados na tabela 11.

Tabela 11 - Resultado dos testes da Etapa 2B - Bateria 3 com a amostra 02 de pellet feed goethítico da Mina de Alegria da Vale

\begin{tabular}{|c|c|c|c|c|c|c|c|c|c|c|c|c|c|c|c|c|c|c|c|}
\hline \multirow{3}{*}{ Amostra } & \multirow{3}{*}{ Teste } & \multicolumn{6}{|c|}{ Condições } & \multirow{3}{*}{ Fluxo } & \multirow{3}{*}{$\begin{array}{c}\mathbf{R} . \\
\text { Mássica } \\
(\%)\end{array}$} & \multicolumn{9}{|c|}{ Quím ica Global (\%) } & \multirow{3}{*}{$\begin{array}{l}\text { Rec. } \\
\text { Metálica } \\
\text { (\%) }\end{array}$} \\
\hline & & \multirow{2}{*}{\begin{tabular}{|c|} 
Temp. \\
oC \\
\end{tabular}} & \multicolumn{2}{|c|}{ Ativador } & \multirow{2}{*}{$\begin{array}{c}\text { Amina } \\
\text { (g/t Alim) } \\
\end{array}$} & \multirow{2}{*}{\begin{tabular}{c|} 
Amido \\
(g/t Alim)
\end{tabular}} & \multirow{2}{*}{$\mathrm{pH}$} & & & \multirow{2}{*}{$\mathrm{Fe}$} & \multirow{2}{*}{ SiO } & \multirow{2}{*}{$\mathbf{P}$} & \multirow{2}{*}{$\mathrm{Al}_{2} \mathrm{O}_{3}$} & \multirow{2}{*}{ Mn } & \multirow{2}{*}{ TiO } & \multirow{2}{*}{$\mathrm{CaO}$} & \multirow{2}{*}{ MgO } & \multirow{2}{*}{ PPC } & \\
\hline & & & Tipo & (g/t Alim) & & & & & & & & & & & & & & & \\
\hline \multirow{16}{*}{ 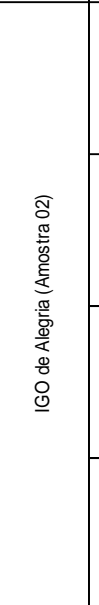 } & \multirow{4}{*}{1} & \multirow{4}{*}{85} & \multirow{4}{*}{$\begin{array}{c}\text { Sulfato de } \\
\text { Sódio }\end{array}$} & \multirow{4}{*}{50} & \multirow{4}{*}{50} & \multirow{4}{*}{1000} & \multirow{4}{*}{7} & AL & 100,00 & 64,13 & 1,24 & 0,040 & 0,41 & 0,096 & 0,028 & 0,008 & 0,046 & 6,26 & \multirow{4}{*}{96,52} \\
\hline & & & & & & & & AL. Calc. & 100,00 & 64,60 & 0,92 & 0,038 & 0,40 & 0,108 & 0,019 & 0,015 & 0,087 & 6,48 & \\
\hline & & & & & & & & $\mathrm{CO}$ & 96,52 & 64,60 & 0,92 & 0,038 & 0,40 & 0,108 & 0,019 & 0,015 & 0,087 & 6,48 & \\
\hline & & & & & & & & RJ & 3,48 & 53,33 & 20,22 & 0,019 & 0,44 & 0,043 & 0,019 & 0,024 & 0,038 & 3,36 & \\
\hline & & & & & & & & AL & 100,00 & 64,13 & 1,24 & 0,04 & 0,41 & 0,10 & 0,03 & 0,01 & 0,05 & 6,26 & \\
\hline & 2 & 85 & Sulfato de & 100 & 50 & 1000 & 7 & AL. Calc. & 100,00 & 64,21 & 1,26 & 0,040 & 0,40 & 0,106 & 0,019 & 0,017 & 0,089 & 6,54 & 8654 \\
\hline & 2 & 00 & Sódio & 100 & 30 & 1000 & r & $\mathrm{CO}$ & 86,39 & 64,32 & 0,95 & 0,041 & 0,40 & 0,109 & 0,019 & 0,017 & 0,091 & 6,66 & 80,04 \\
\hline & & & & & & & & RJ & 13,61 & 61,88 & 7,83 & 0,023 & 0,39 & 0,046 & 0,026 & 0,017 & 0,055 & 4,04 & \\
\hline & & & & & & & & $\mathrm{AL}$ & 100,00 & 64,13 & 1,24 & 0,04 & 0,41 & 0,10 & 0,03 & 0,01 & 0,05 & 6,26 & \\
\hline & 3 & 85 & Sulfato de & 100 & 100 & 1000 & 7 & AL. Calc. & 100,00 & 64,94 & 1,04 & 0,037 & 0,36 & 0,110 & 0,018 & 0,010 & 0,090 & 6,21 & 96.28 \\
\hline & 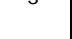 & 00 & Sódio & 100 & 100 & 1000 & r & $\mathrm{CO}$ & 96,13 & 65,04 & 0,84 & 0,037 & 0,36 & 0,111 & 0,018 & 0,010 & 0,091 & 6,27 & $0,<0$ \\
\hline & & & & & & & & RJ & 3,87 & 55,99 & 17,98 & 0,009 & 0,41 & 0,005 & 0,020 & 0,026 & 0,024 & 1,45 & \\
\hline & & & & & & & & AL & 100,00 & 64,13 & 1,24 & 0,04 & 0,41 & 0,10 & 0,03 & 0,01 & 0,05 & 6,26 & \\
\hline & 4 & 85 & Sulfato de & ח & 100 & 1000 & 7 & AL. Calc. & 100,00 & 64,39 & 0,93 & 0,042 & 0,38 & 0,114 & 0,017 & 0,008 & 0,077 & 6,76 & 8266 \\
\hline & 4 & 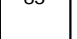 & Sódio & 200 & 0 & 1000 & r & $\mathrm{CO}$ & 82,65 & 64,40 & 0,90 & 0,042 & 0,38 & 0,115 & 0,017 & 0,008 & 0,077 & 6,77 & $0<, 00$ \\
\hline & & & & & & & & RJ & 17,35 & 63,27 & 4,64 & 0,027 & 0,41 & 0,048 & 0,031 & 0,021 & 0,055 & 4,85 & \\
\hline
\end{tabular}

Fonte - Lipper, 2012.

Da tabela 11 podem ser extraídas as seguintes conclusões: 
- Os teores de Fe nos concentrados de todos os testes ficaram iguais do ponto de vista de performance, ou seja em média $=64,60 \% \mathrm{Fe}$, aumentando em 0,4\% Fe em relação à alimentação;

- O aumento da dosagem de sulfato de sódio de 50 para $100 \mathrm{~g} / \mathrm{t}$ de alimentação melhorou a flotação de hematita;

- O aumento de dosagem de amina de 50 para $100 \mathrm{~g} / \mathrm{t}$ de alimentação prejudica a seletividade da flotação.

Para entender melhor a flotação da Etapa 2B - Bateria 03 foi feitas as caracterizações mineralógicas dos produtos dos melhores testes gerados nas Baterias 02 e 03 e pode-se concluir 0 seguinte:

- A maioria dos minerais flotados foi: hematita e quartzo;

- A razão de o quartzo ter sido flotado em pH = 7 não é ainda explicável;

- A hematita foi flotada $\mathrm{pH}=7$ porque uma vez que, nesse valor de $\mathrm{pH}$, o sulfato de sódio age preferencialmente nas superfícies das hematitas do que na superfície das goethitas.

- Os cristais das goethitas flotadas são bem menores que os cristais das goethitas que ficaram no concentrado. Esses dois fatores explicam a causa do menor PPC no fluxo de rejeito (flotado).

\section{CONCLUSÕES}

Na flotação catiônica reversa de minério de ferro, a separação em 0,045mm aumenta a recuperação mássica da flotação sem comprometer a qualidade a utilização de ácido oleico e o uso de ultrassom não apresentaram benefício à flotação.

Quanto maior o nível de hidratação da amostra, maior é o efeito do sulfato de sódio.

O sulfato de sódio em $\mathrm{pH}=7$ se comporta como ativador de superfície para separar partículas de goethitas das hematitas, pois ele individualmente no sistema não atua como coletor devendo ser utilizada amina.

O aumento da temperatura melhora a ação do sulfato de sódio atuando como ativador de superfície da hematita.

\section{REFERÊNCIAS BIBLIOGRÁFICAS}

1. CILEK E.C., OZGEN S. Effect of ultrasound on separation selectivity and efficiency of flotation, Minerals Engineering, v. 22, n. 14, p. 1209-1217, 2009.

2. CASTRO, E.B., CRUZ, M.R. Modificação do circuito de flotação da planta de beneficiamento de Vargem Grande. Anais do IV Simpósio Brasileiro de Minério de Ferro e XXXIII Seminário de Redução de Minério de Ferro e Matérias Primas da ABM, p.580-588, Ouro Preto, Brasil, 2003.

3. HENRIQUES, A.B. Caracterização e estudo das propriedades eletrocinéticas dos minerais de ferro: hematita, goethita e magnetita. Tese de Doutorado em Engenharia Metalúrgica de 
Minas. Programa de Pós-Graduação em Engenharia Metalúrgica, Materiais e de Minas, Universidade Federal de Minas Gerais, p. 223, 2012.

4. IWASAKI, I., COOKE S.R.B., COLOMBO, A.F. U.S. Bureau of Mines, Report of investigations (RI 5593) p.1- 23, 1960.

5. LIMA, N.P. Avaliação do processo de flotação para diferentes frações granulométricas. Tese de Doutorado em Engenharia Metalúrgica de Minas. Programa de Pós-Graduação em Engenharia Metalúrgica, Materiais e de Minas, Universidade Federal de Minas Gerais, p. 160, 2010.

6. LIPPER, G.C. Rota de processo para concentração de minérios de ferro hidratados. Dissertação de Mestrado em Tecnologia Mineral. Programa de Pós-Graduação em Engenharia Metalúrgica, Materiais e de Minas, Universidade Federal de Minas Gerais, p. 19 - 148, 2012.

7. RABOCKAI, T. Físico-química de Superfícies, OEA, Washington, Cap.2, p. 10, 1979.

8. SANTOS, G. Informações geológicas e amostras para caracterização do minério do Projeto Apolo, Relatório interno da Vale, 2006.

9. VALE, GADMF Documento interno da Vale: Dados básicos e critérios de projetos, RG0002 GADMF N0007_Apolo_rev04, 2010. 